\title{
Mechanical Erosion and Reheating of the Lithosphere: A Numerical Model for Hotspot Swells
}

\author{
Marc Monnereau AND Michlil. Rabinowicz \\ Groupe de Recherche en Géodésie Spatiale, Observatoire Midi-Pyrénées, Toulouse, France
}

\section{ERIC ARQUIS}

Madelisation Avancée des Systèmes Thermiques et Ecoulements Réels, Ecole Nationale Supérieure de Chimie et de Physique de Bordeaux, Talence, France

\begin{abstract}
It is currently debated if either thermal erosion of the lithosphere or dynamical support is the source of topography and geoid anomalies. The origin of this controversy lies probably in the difficulty to model simultaneously these two effects. For this purpose we have studied the time dependent behavior of two-dimensional convection with a temperature and pressure dependent viscosity. The use of a control volume method allows us to define a rigid zone simulating the mechanical lithosphere. The interface between the lithosphere and the convective mantle is determined by a viscosity culoff. First, some experiments model the rise of a plume below the lithosphere in order to observe the evolution of the uplift and thus to appreciate the various processes involved in the swell formation. Before the plume reaches the base of the thermal lithosphere, an uplift a few hundred meters in amplitude develops which can only be ascribed to a pure dynamical support. The major uplift occurs when the ductile part of the lithosphere, the convective boundary layer, is squeezed by the plume.The reheating of the mechanical lithosphere takes place after this transient stage of dynamical erosion. However, this late process is very slow but can magnify the amplitude of the swell if the lithosphere stays long enough above the plume. These results shed some light on the different mechanisms occurring during the swell formation, but the configuration modeled does not correspond to the one expected for actual hotspot swells. They feature plume rising up to the lithosphere while natural situations correspond to lithosphere drifting above preexisting plumes. An experiment with a moving lithosphere was run and shows that thermal erosion does not affect significantly a moving lithosphere even for relatively slow drifting velocities (few centimeters/year). Indeed, the thermal structure of the lithosphere is not modified above the $800^{\circ} \mathrm{C}$ isotherm except for a motionless plate. In this case the resulting swell should be greater: this could explain why Azores, Crozet or Cap Verde swells are so high. On the other hand, the shape of a swell over a moving lithosphere is strikingly reminiscent of the Hawaiian swell.
\end{abstract}

\section{INTRODUCTION}

Hotspots are generally considered as one of the surface expressions of mantle convection, an hypothesis which is mainly supported by their quasi-fixity relative to each other [Morgan, 1971]. In spite of this general agreement, the mechanisms which account for the large topographic swells surrounding the hotspots have never been clearly elucidated. It was first proposed that they were dynamically supported by the upwelling currents themselves, but constant viscosity numerical models failed to account for the weak geoid to depth ratios (GDR) measured above oceanic swells. Density anomalies located inside the lithosphere were apparently required by these data. An alternative model was developed by Crough [1978] who proposed that swells exclusively result from the thermal rejuvenation of the lithosphere as it passes above a mantle plume. This model was supported by the shape of the Hawaiian swell: a bathymetric profile away from Hawaiian

\section{Copyright 1993 by the American Geophysical Union.}

Paper number 92JB01677. 0148-0227/93/92JB-01677\$05.00 island is similar to the subsidence profiles observed away from oceanic ridges. Subsequently, McNutt has shown that the amplitude of a significant amount of hotspot swells could be entirely explained by a thermal perturbation of the lithosphere [e.g., McNutt, 1987].

In spite of their attractive simplicity, thermal models fail to explain a major characteristic of hotspot swells: they develop during a few million years, which is short compared to the characteristic time constants associated with conduction of heat in the lithosphere. To get around this difficulty, Yuen and Fleitout [1985] suggested that the lithospheric thinning accountable for the swell formation results from small-scale convection developing at the top of the plume where the viscosity could drop by 4 orders of magnitude.

As a matter of fact, Robinson et al. [1987] have shown that a viscosity drop at the top of a convective current results in very weak or even negative GDR, depending on the magnitude of the viscosity contrast. A worldwide survey of GDR above the major oceanic hotspot swells has revealed a systematic increase of the GDR according to the square root of the age of the plate affected by the hotspot [Monnereau and Cazenave,1988]. Ceuleneer et al. [1988] have shown that such a trend was very useful to constrain the viscosity structure of the mantle beneath hotspot 
swells. Their best estimates for the magnitude of the viscosity drop and for the depth where it occurs are 1/50 and $220 \mathrm{~km}$, respectively. The GDR variation with plate age is naturally accounted for by lithospheric thickening, all other parameters remaining constant.

It is worth noting that the observed GDR are weaker than those computed by McNutt and too weak to be attributable to a thermal thinning model. They correspond to compensation depths (i.e., to an apparent depth of the center of mass anomaly) located close to the $600^{\circ} \mathrm{C}$ isotherm while a lithospheric thinning up to the $700^{\circ} \mathrm{C}$ isotherm is largely sufficient to account for the topographic signals [Monnereau and Cazenave, 1990]. Beyond the problem of explaining the amplitude of the geoid-to-depth ratio, Von Herzen et al. [1989] have shown that Hawaiian swell is not associated with a heat flow anomaly as expected in the case of a pure thermal thinning. This is evidence for a dynamic contribution to the swell.

From this short review, it appears that neither purely dynamical nor purely thermal mechanisms account for observations at hotspot swells. These structures likely result from the complex interaction between a mantle plume and the lithosphere. Unfortunately, both thermal and dynamical aspects of this process cannot be taken easily into account in the same model. The origin of the controversy between the thermal and the dynamical schools can probably be found in these methodological difficulties. A more promising approach has been adopted by Olson and Schubert [1988] who developed time-dependent models of the interaction between a mantle upwelling and the lithosphere. They tried to determine the conditions for rapid and significant erosion of the lithosphere. This is also the goal of the present study. In addition, we include in our models accurate computation of the topographic and geoid response of the plume-lithophere interaction.

\section{CONVECTIVE Model.}

In problems dealing with the thermo-mechanical coupling between the lithosphere and the asthenosphere, the lithosphere can, following Schmeling [1991], be defined as that part of the mantle which is not involved in convective movements, i.e., where the rock deformation is not significant even in response to long-term applied stresses. It is hereinafter referred to as mechanical lithosphere. In the present study we assume that this corresponds to deformation rates, $\varepsilon$, lower than $10^{-16} \mathrm{~s}^{-1}$, i.e., a deformation of $3 \%$ during a period of 10 m.y. The shear stress observed at the base of the lithosphere in numerical experiments [e.g., Rabinowicz et al., 1980] does not exceed $5 \mathrm{MPa}$. Even lower values are found in the present experiment. Therefore the maximum deformation rate prescribed above occurs for effective viscosity smaller than $5 \times 10^{22} \mathrm{~Pa}$ s. Accordingly, in the model, a viscosity cut-off is set to this value. Above, an infinite value is ascribed to the viscosity.

In the plastic domain of the box, we model twodimensional infinite Prandtl number thermal convection employing the Boussinesq approximation. In dimensionless form, the equations of mass, energy and momentum conservation are, respectively,

$$
\frac{\partial v_{x}}{\partial x}+\frac{\partial v_{z}}{\partial z}=0
$$

$$
\begin{gathered}
\frac{\partial P}{\partial x}=2 \frac{\partial}{\partial x}\left(\eta \frac{\partial v_{x}}{\partial x}\right)+\frac{\partial}{\partial z}\left(\eta\left(\frac{\partial v_{x}}{\partial z}+\frac{\partial v_{z}}{\partial x}\right)\right) \\
\frac{\partial P}{\partial z}=R a T+2 \frac{\partial}{\partial z}\left(\eta \frac{\partial v_{z}}{\partial z}\right)+\frac{\partial}{\partial x}\left(\eta\left(\frac{\partial v_{x}}{\partial z}+\frac{\partial v_{z}}{\partial x}\right)\right), \\
\frac{\partial T}{\partial t}+v_{x} \frac{\partial T}{\partial x}+v_{z} \frac{\partial T}{\partial z}=\frac{\partial^{2} T}{\partial x^{2}}+\frac{\partial^{2} T}{\partial z^{2}}
\end{gathered}
$$

where $v_{x}$ and $v_{z}$ are horizontal and vertical components of the fluid velocity, $P$ the deviation of pressure relative to the hydrostatic value $\rho_{m} g z, T$ the deviation of temperature relative to the reference temperature $T_{0}, \eta$ the ratio between the actual viscosity of the fluid and a reference viscosity, $\eta_{0}$. which is taken on the bottom of the model box, and $R a$ the Rayleigh number defined as

$$
R a=\frac{\rho_{m} g a L^{3} \Delta T}{\kappa \eta_{0}}
$$

(definition and value of the constants as in Table 1). Flow and temperature fields are periodic in the horizontal direction. Isothermal conditions are taken at the top and bottom boundaries and no slip conditions along the bottom and the lithosphere-asthenosphere interface.

These equations were solved following a numerical scheme developed by Arquis and Caltagirone [1987] who use a control volumes method to discretize the equations [Patankar, 1980]. The grid consists of 90 regularly spaced vertical points and 64 or 96 horizontal points for boxes with an aspect ratio of 2 and 3 respectively. The primitive variables $v_{x}, v_{z}$ and $T$ were calculated using an alternate direction inversion method. Pressure was obtained by an artificial compressibility method.

\section{Topography and Geoid}

To calculate the topographic deflection associated with the plume, it is necessary to determine the stresses acting on the elastic part of the lithosphere. In the model, the stress field induced by the convective flow is known along the lithosphere-asthenophere interface, which, as it is defined, does not correspond to the base of the elastic lithosphere. Of course little ductile deformations may still take place between these two boundaries. They will not affect the dynamics in the underlying mantle, but they could somewhat attenuate the level of stresses transmitted through this horizon. Fleitout and Moriceau [1991] have shown that this attenuation depends on both the viscosity profile in this layer and the ratio of the layer thickness to the horizontal wavelength of the stress field. However this effect is particulary noticeable for short wavelength structure. In the present experiments the wavelength of stresses are very large, about $1000 \mathrm{~km}$, relatively to the thickness of the highly viscous part of the lithosphere which never exceeds $50 \mathrm{~km}$ : the lithosphere-asthenosphere boundary is lying between the $700^{\circ} \mathrm{C}$ and the $900^{\circ} \mathrm{C}$ isotherm, whereas the elastic thickness deduced from studies of lithospheric flexure under the load of seamounts follow the empirical relationship:

$$
H=2.7 \sqrt{\mathrm{age}},
$$


which corresponds to the depth of the $400^{\circ} \mathrm{C}$ isotherm [Calmant et al., 1990]. According to Fleitout and Moriceau's results, the transmission of stresses, in the present cases, should be larger than 97\%. Actually, we have neglected this effect, which implies an overestimation of the topography and of the geoid by a few percent for a 100 -Ma-old plate and at most $5 \%$ for a very old plate. This does not affect significanlly the estimation of the geoid to depth ratios.

Because of no slip conditions both vertical and shear stress support the topography. The vertical stress applied to the elastic part is equal to the pressure at the asthenosphere-lithosphere interface diminished by the weight of the lithosphere. The topography can be derived from the following equation [Fleitout and Moriceau, 1991]:

$$
\begin{gathered}
\left(\rho_{m}-\rho_{w}\right) g \frac{1+\operatorname{sh}(k H) \operatorname{ch}(k H)}{\operatorname{sh}(k H)+k H \operatorname{ch}(k H)} \hat{h}(k)+ \\
\frac{E}{2\left(1-v^{2}\right)} \frac{k\left(s^{2}(k H)-k H^{2}\right)}{\operatorname{sh}(k H)+k H \operatorname{ch}(k H)} \hat{h}(k) \\
=\widehat{P}(k)_{I}-\rho_{m} g \alpha \int_{0}^{I} \widehat{T}(k, z) d z+\frac{k H \operatorname{sh}(k H)}{\operatorname{sh}(k H)+k H \operatorname{ch}(k H)} \hat{\tau}_{x z}(k)_{l},
\end{gathered}
$$

where $\hat{h}, \hat{P}, \widehat{T}$ and $\hat{\tau}_{x z}$ are the Fourier transform in the horizontal direction of the topography, the pressure, the temperature and the shear stress, respectively, $I$ is the interface depth, $E$ the Young modulus and $v$ the Poisson ratio.

Note that this equation corresponds to the thick plate approximation and, although the wavelength of the thermal and pressure structure are large relative to the elastic thickness, it yields amplitudes about $10 \%$ smaller than in the thin plate approximation. On the other hand, the shear stresses produced by the convective flow at the top being of the order of a few megapascal, their contribution to the topography is quite negligible. 1983]

The geoid anomaly is given by [e.g., Parsons and Daly,

$$
\hat{N}(k, z)=\frac{2 \pi G}{g}\left[\left(\rho_{m}-\rho_{w}\right) \hat{h}(k)-\rho_{m} \alpha \int_{0}^{L} \frac{1}{k} e^{k z^{\prime}} \widehat{T}\left(k, z^{\prime}\right) d z^{\prime}\right],(8)
$$

where $\widehat{T}, \hat{h}$ and $\widehat{N}$ are the Fourier transform in the horizontal direction of the temperature, the topography and the geoid anomaly, respectively.

\section{Viscosity Law}

To set the viscosity law is critical for the experiments presented below. Mantle rocks are characterized by a viscosity which is temperature, pressure and stressdependent. These three parameters do not affect the mantle viscosity in a similar way and may have opposite effects. For instance, the viscosity is very sensitive to temperalure variations at shallow depth but the importance of this parameter is strongly reduced in the case of a stress dependent viscosity. Accordingly, convective experiments with a power law viscosity proportional to the third power of the stress result in similar convective patterns than experiments with a Newtonian viscosity where temperature and pressure dependence is reduced by a factor of 2 to 4 [Christensen, 1984]. As far as geoid and topography data are concerned, several observations support the existence of a sublithospheric low-viscosity zone (LVZ) where the viscosity drops by a factor 10 to 100 [Cathles, 1975; Craig and McKenzie, 1986; Robinson et al., 1988; Marty et al., 1988]. In the present study we have not considered all these parameters separately. Our approach was to set a viscosity law accounting for the three following constraints: 1) the viscosity cut-off lies between the $700^{\circ} \mathrm{C}$ and the $900^{\circ} \mathrm{C}$ isotherm, consistent with the tempcrature usually estimated at the base of the mechanical lithosphere; 2) a viscosity drop of $1 / 50$ is achieved in the core and at the top of the plume; 3 ) the viscosity of the mantle away from the plume is as homogeneous as possible. These conditions are roughly satisfied with a Newtonian viscosity where the activation volume and energy is reduced by a factor of 4 relative to the values generally estimated for the mantle from experiments [e.g., Kirby, 1983]. The nondimensional form of this law is

$$
\eta=\eta_{0} \exp \left(\frac{10+7 z}{T+.17}\right)
$$

The viscosity reference at the bottom of the box is equal to $2.510^{20}$, a value which yields a Rayleigh number of $10^{6}$.

The experiments presented below are in some extent analogous to those computed by Olson and Schubert [1988]: we observe the development and the rise of a convective instability in a thermal fluid consistent with the formation of an oceanic lithosphere by conductive cooling of an half-space model:

$$
T=T_{m} \operatorname{erf}\left(\frac{z}{2 \sqrt{\mathrm{Kage}}}\right),
$$

where $T_{m}$ is the mean temperature in the mantle. The temperature at the bottom boundary is set to $1800^{\circ} \mathrm{C}$. In order to allow the formation of a single plume, the initial condition for temperature contains a small rot anomaly near the bottom (cf. Figure 1).

\section{NUMERICAL. EXPERIMENTS}

In the first experiment, the instability initiates as the overlying lithosphere is $10 \mathrm{~m} . \mathrm{y}$. old. The growth and evolution of this instability during a period of 100 m.y. are presented in Figure 1. Four cartoons allow us to follow simultaneously the evolution of the thermal field, the viscosity field, the geoid and topography and, for the upper third part of the box, the temperature deviation relative to the thermal field of the half-space cooling model.

After a relatively long period of time, 55 to $60 \mathrm{~m} . y$., the plume reaches the base of the lithosphere. The $1300^{\circ} \mathrm{C}$ isotherm is slightly deformed but the amplitudes of surface observables are still relatively weak : the topographic swell is $250 \mathrm{~m}$ in amplitude and the geoid anomaly is $1 \mathrm{~m}$. This stage is followed by a short episode, lasting less than 10 m.y., characterized by the intrusion of the plume in the convective boundary. Most of the final amplitude of the swell topography and of the geoid anomaly is acquired during this stage $(850 \mathrm{~m}$ for the lopography and $5 \mathrm{~m}$ for 
the geoid anomaly). At that time, the progression of the plume becomes more and more sluggish; conduction becomes the dominant heat transport mechanism. Then during 10-15 m.y. (from 75 m.y. to 90 m.y.), while the plume material is spreading beneath the lithosphere, geoid and topography do not present any significant evolution. They widen, while the peak value does not change. Their progressive increase is observed later on (between 90 and $110 \mathrm{~m} . y$.$) . Topography grows from 850 \mathrm{~m}$ to $1300 \mathrm{~m}$ in amplitude and the geoid anomaly increases from a value of $5 \mathrm{~m}$ to $6.5 \mathrm{~m}$. The base of the mechanical lithosphere has shifted a few kilometers upward but the thermal anomaly has not reached the surface.

The evolution of the geotherm in the center of the plume and of the surface observables are shown in Figure 2. It summarizes the preceding story and stresses the relative importance of the two processes involved in the swell formation: the squeezing of the ductile part of the lithosphere, as a "mechanical erosion," and the reheating of its rigid part. It allows us to visualize the contrasting times constants characterizing each of these processes: the first one is very short ( $<10 \mathrm{~m} . \mathrm{y}$.) while the second one is more sluggish, requiring several tens of millions of years to develop observable effects.

\section{Geoid and Topography Versus the Age of the Plate}

Several studies have shown that the amplitude of hotspot swells and of the associated geoid anomaly are related to the lithospheric cooling. In Figure 3, derived from a set of measurements performed at 23 oceanic hotspot swells [Monnereau and Cazenave, 1990], are plotted the swell heights and the associated geoid anomalies versus plate age. The data cluster around an average trend of increasing amplitude with age (gcoid) or square root of age (lopography). Three hotspots significantly depart from this general tendency: Azores, Crozet and Cap Verde.

In order to test if our model can account for this puzzling observation, we have performed an experiment similar to the preceding one but initiated with a much older lithosphere (i.e., 110 m.y.).

In Figures 4 and 5 (equivalent to Figures 1 and 2), we recognize the different steps of the evolution of the interaction put in evidence in the first experiment, particulary the two stages responsible for the swell formation. In the present case, surface observables display a significantly higher value. When the lithosphere is 185 m.y. old, the evolution of the geotherm in the center of the plume (Figure 5) indicates that the mechanical erosion seems achieved. However, the geoid anomaly and the topography are still increasing during $5 \mathrm{~m} . \mathrm{y}$. At this stage, the topographic deflection is $1250 \mathrm{~m}$ and the geoid anomaly is $10 \mathrm{~m}$. At the end of the experiment, $40 \mathrm{~m} . y$. later, the topography has reached a value of $1450 \mathrm{~m}$ and the geoid has decreased until the value of $7.5 \mathrm{~m}$.

Cases where the lithosphere remains fixed relative to the hotspot reference frame during a period of several tens

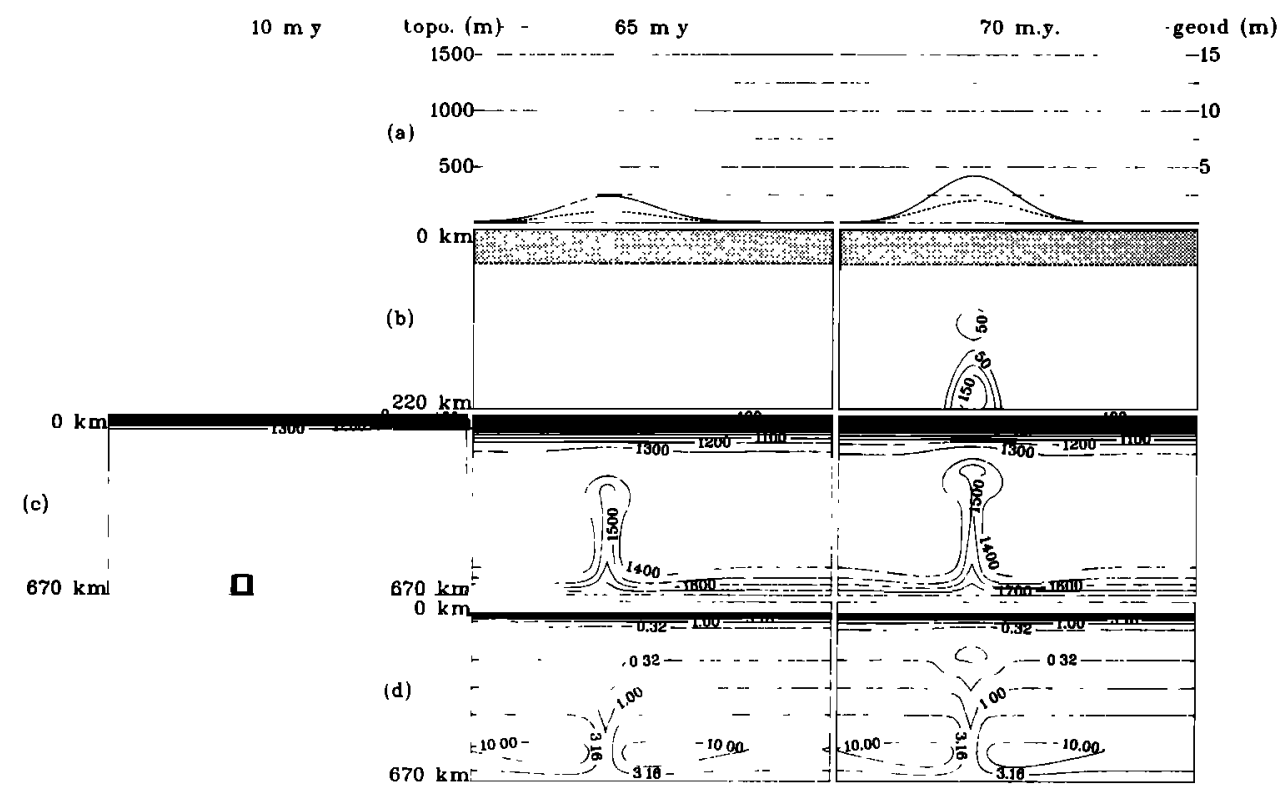

Fig. 1. Plume-lithosphere interaction with Newtonian rheology and basal heating. First experiment: $E^{*}=130 \mathrm{~kJ} \mathrm{~mol}^{-1}, V c=4 \mathrm{~m}^{3} \mathrm{~mol}^{-1}$, the lithosphere is $10 \mathrm{~m} . \mathrm{y}$. old at the start of the experiment. (a) Topography (solid curves) and geoid anomaly (dashed curves) induced by the convective flow and the temperature anomaly inside the lithosphere. (b) Detail, for the upper third of the box, of the thermal anomaly brought by the plume, i.e., the temperature deviation relative to the thermal field of the half-space cooling model (in degrees Celcius). The shaded area indicates the "mechanical lithosphere" where, in this model, the viscosity takes an infinite value. (c) Temperature ficld (in degrees Celcius). (d) Viscosity field. The uplift initiates before the plume reaches the lithosphere, which can be only ascribed to a pure dynamical support. The main uplift is induced by the squeezing of the convective boundary layer from $70 \mathrm{~m}$.y. to 75 m.y. At the end of the experiment, after $30 \mathrm{~m} . \mathrm{y}$. of conductive healing, the thermal anomaly is well inside the mechanical lithosphere and produces an additional uplift. Note the base of the mechanical lithosphere has moved upward as a result of thermal erosion. 
of millions of years are not very frequent. Accordingly, we have compared the observed geoid and topography anomalies to the one computed after the mechanical erosion, just at the end of the first stage of swell formation. The fit is roughly satisfactory for the topography, but the computed geoid anomaly exceeds the observed ones by a factor of 1.5 to 2 . In spite of this, the geoid amplitudes remain proportional to the age of the plate.

It is worth noting that the three hotspots lying above the average trends are located since a long period of time on plates, which are almost motionless with respect to the hotspot reference frame. Thus their swell amplitude could be ascribed to an important reheating as observed in the last few snapshots of experiment 1 and 2 (Figures 1 and 4).

\section{GDR and Compensation Depth}

The geoid to depth ratios compuled in the present study are higher than the observed ones. They are definitely
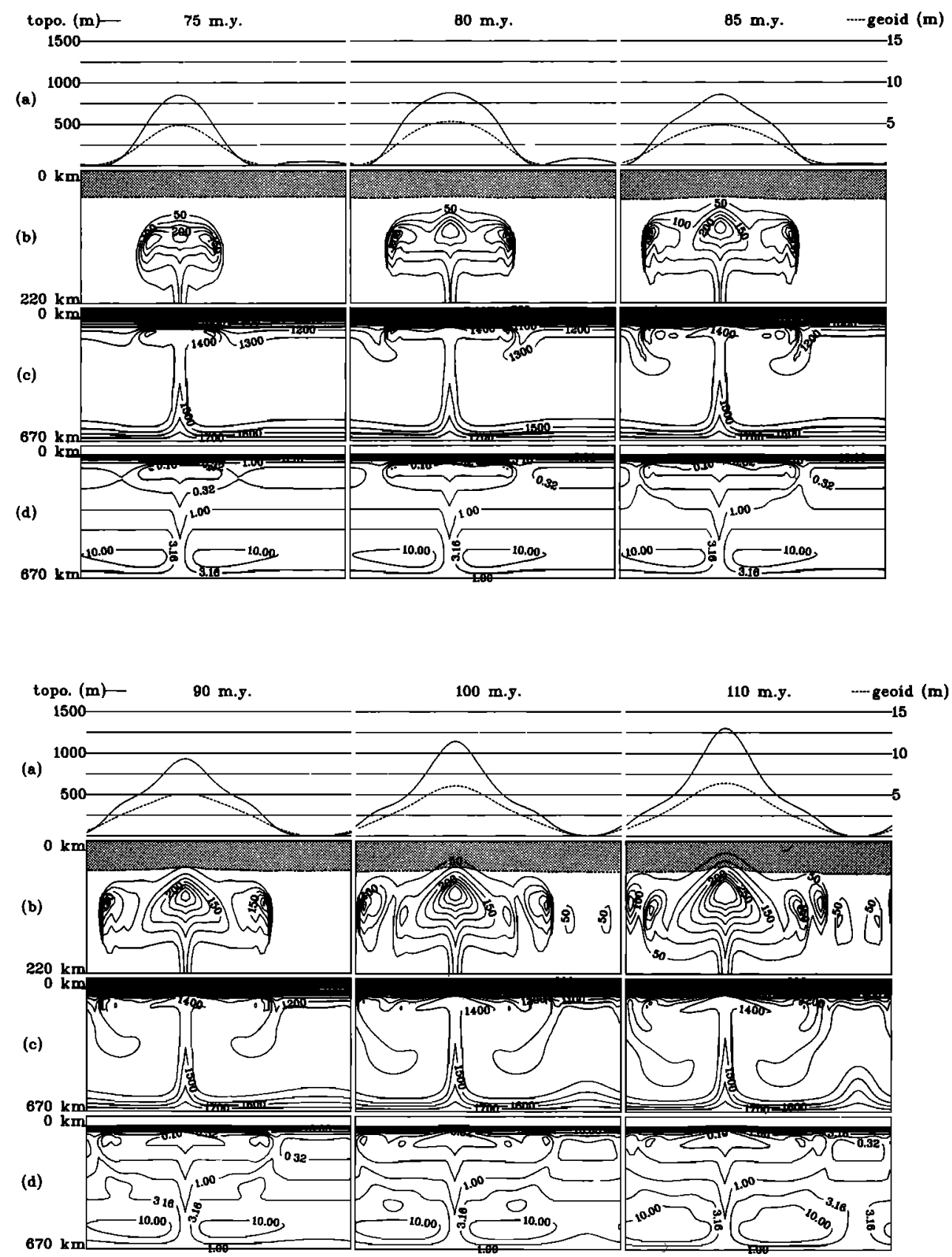

Fig. 1. (continued) 


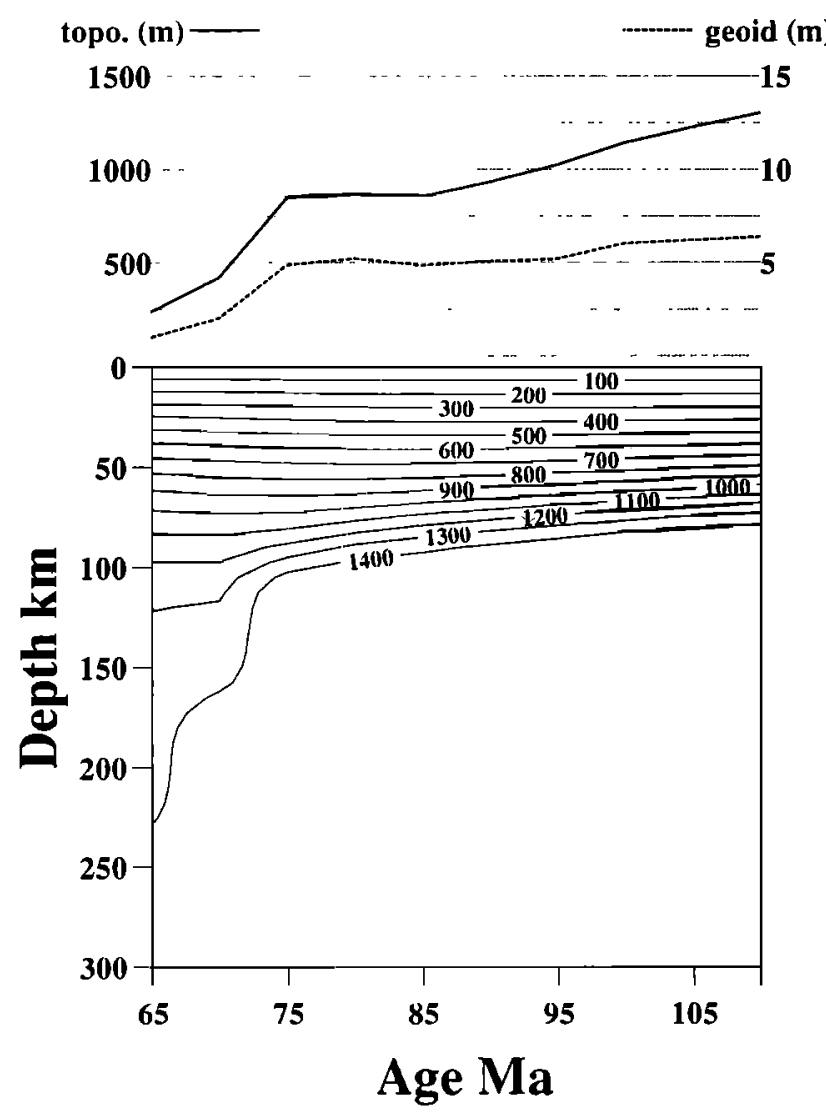

Fig. 2. Evolution of the temperature profile through the center of the plume for the first experiment (shown in Figure 1). Two stages of interaction can be distinguished producing $2 / 3$ and $1 / 3$ of the final uplif, respectively; a rapid dynamical erosion followed by a much more sluggish conductive reheating.

smaller than the unrealistic values derived from the early convective models with constant viscosity.

In the frame of a two-layer convection model, where the lithosphere grows at the expense of the LVZ, Ceuleneer et al. [1988] have computed GDR variations as a function of the lithospheric thickness and of the magnitude of the viscosity ratio between the $L V Z$ and the underlying mantle (Figure 6a). The GDR values and conductive lid thickness derived from our two experiments (1 and 2) would correspond to viscosity ratios of about 20 , in the twolayers model. These values are consistent with the viscosity increase occurring below the lithosphere in the present experiment (see Figures $6 \mathrm{~b}$ and $6 \mathrm{c}$ ). This agreement likely results from the similarity of the viscosity field in both generations of models: one can observ in Figure 1 and Figure 4 that the viscosity fields are dominated by an horizontal stratification with a minimum just bclow the lithosphere. In the two-layers model, when the viscosity contrast remains constant, the increase of the GDR results both from a thickening of the lithosphere and from the resulting thinning of the low-viscosity zone. Since the viscosity structure of experiments 1 and 2 are identical below the minimum, the GDR increase from experiment 1 to experiment 2 can only be ascribed to a thickening of the lithosphere.

Motivated by this result, we have performed a third experiment similar to the second one but with a viscosity which is less pressure dependent, in order to reduce the viscosity variations beneath the lithosphere. This law,

$$
\eta=\eta_{0} \exp \left(\frac{5+1.5 z}{T+.17}\right)
$$

leads to the case presented in Figure 7. The interaction process between the plume and the lithosphere are significantly modified by this alteration of the viscosity law. The sudden squeezing of the thermal boundary layer is no longer observed. This stage is superseded by a slow penetration of the plume in the lithosphere during a period of 20 to 25 m.y. A similar result was previously found by Olson and Schubert [1988] who noted that the stronger the pressure dependence of the viscosity, the more efficient the erosion of the lithosphere. Surface observables allow us to follow the evolution of the swell which is now more gradual (see Figure 8). Around 200 m.y., it reaches an amplitude of $1250 \mathrm{~m}$ and the associated geoid anomaly is $13 \mathrm{~m}$. The GDR is $10 \mathrm{~m} / \mathrm{km}$ which corresponds to viscosity ratios lower than 10 of the two-layers models (Figure 6). This is in agreement with the viscosity variations computed in this experiment.

The two-layers models have shown the dependence between the viscosity contrast and the GDR: the higher viscosity contrast, the lower the GDR. Accordingly, a more pressure dependent viscosity might lead to a best fit with the actual GDR.

What interpretation in terms of compensation can be derived from the GDR associated with these convective flows? For instance, let us have a look at the situation depicted in Figure 1, at 65 m.y., while the plume has not reached the base of the lithosphere yet. At this stage, the thermal anomaly is located at a depth $>200 \mathrm{~km}$ and the associated GDR is lower than $5 \mathrm{~m} / \mathrm{km}$. Such a low GDR value could be interpreted in terms of a compensation depth less than $50 \mathrm{~km}$ ! (The term compensation depth can be interpreted in different ways depending on which isostatic mechanism is invoked, Airy, Pratt, etc.; here we prefer the simplest definition: the depth of the center of mass anomaly responsible for the topography which is the expression of the moments law expressed by Haxby and Turcotte [1978].) Besides, this value remains roughly constant during the mechanical erosion (Figure 2). This is not so surprising. It is well known that in the case of a dynamical system, the interpretation of GDR data in terms of isostasy leads to an aberrant localization of the center of the mass anomaly responsible for the surface observables. Indeed, the GDR seems more related to the viscosity structure below the lithosphere than to the aclual location of the temperature anomalies.

Accordingly, no important lithospheric thinning needs to be invoked to explain the low apparent compensation depth at hotspot swells. In return, the squeezing of the ductile part of the lithosphere, i.e., the part located deeper than the $800^{\circ} \mathrm{C}$ isotherm, can account for the rapid formation of the swells, for their topographic amplitude and for plate age dependence of the topography and the associated geoid anomaly. Consequently, a mechanical erosion appears to be the dominant mechanism responsible for the swell formation.

\section{Case of a Moving Plate}

The situation considered before departs from the actual one. We model the rise of a plume beneath a lithosphere. Actual situations correspond to a lithosphere sliding toward a preexisting plume. 

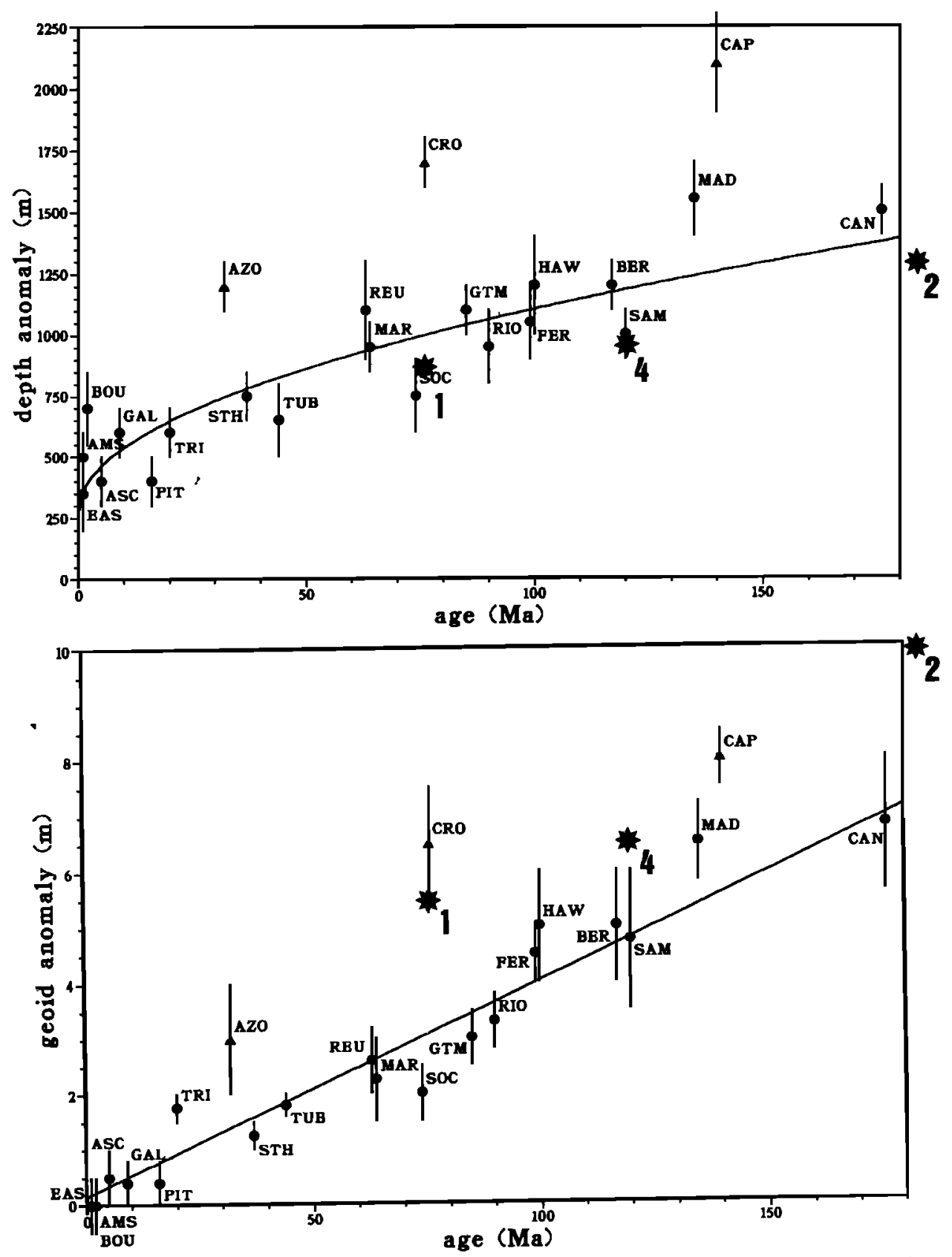

Fig. 3. (a) Swell height and (b) geoid anomaly amplitude as a function of age of plate: comparison of the computed values (asterisks) with actual values (circles) for 23 hotspots. These estimations have been made on radial profile cutting the hotspot (see Monnereau and Cazenave [1990]). The experimental values have been taken just after the squeezing of the convective boundary layer for experiments 1,2 and 4 . These cases correspond to the same viscosity law $\left(E^{*}=130 \mathrm{~kJ} \mathrm{~mol}^{-1}, V c=4 \mathrm{~m}^{3} \mathrm{~mol}^{-1}\right)$ but for various age of plate at the start of the experiment (shown in Figures 1,4 and 9). The increase of the actual amplitudes with age may be explained by the thickening of the erodible part of the lithosphere with age. Note that Azores (AZO), Crozet (CRO) and Cape Verde (CAP) lie well above the average trend. They are located on a motionless plate and their anomalously high swell may be due to an important reheating of the lithosphere as in Figures 1 and 4. This effect is not observed on a moving plate as shown in Figure 9.

Accordingly, we have performed a last experiment including a moving plate (Figure 9). The drift velocity has been fixed at $2 \mathrm{~cm} / \mathrm{yr}$ only to limit the horizontal extension of the box. Due to computational limitations, the aspect ratio of the box was limited to 3 in order to conserve both vertical and horizontal resolutions with the same precision than in the previous experiments (grid steps of $7.5 \mathrm{~km}$ and $10.5 \mathrm{~km}$, respectively). We are thus able to follow during 100 m.y. the evolution of the convection before the lithosphere comes back above the plume.The experiment is started with a 50-m.y.-old lithosphere. The viscosity law is the same as for experiments 1 and 2 . The plume is not significantly disturbed by the drift as long as it has not reached the lithosphere. As in the case of the first experiments, the squeezing of the convective boundary layer is very fast $(<10 \mathrm{~m} . \mathrm{y}$.). The surface observables at this stage, 120 m.y., are bracketed by the ones of experiments 1 and 2 and corroborate their already noted plate age dependence (cf. Figure 3).

Subsequently, during the last $40 \mathrm{~m} . \mathrm{y}$. of the 

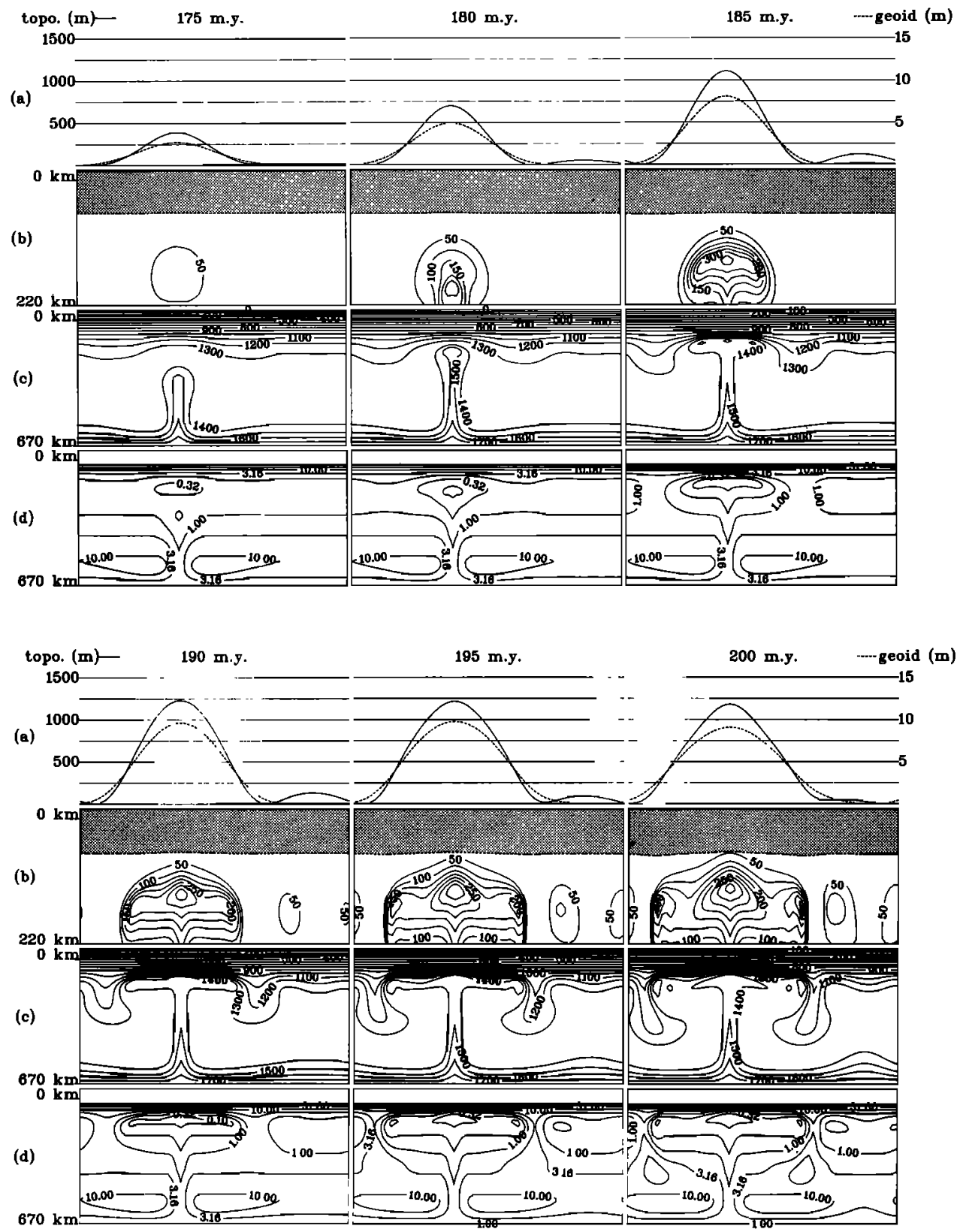

Fig. 4. Plume-lithosphere interaction with newtonian rheology and basal heating. Second experiment: $E^{*}=130 \mathrm{~kJ} \mathrm{~mol}^{-1}, V c=4 \mathrm{~m}^{3} \mathrm{~mol}^{-1}$, the lithosphere is $110 \mathrm{~m} . \mathrm{y}$. old at the start of the experiment. Same features as in Figure 1 are observable : first, a rapid squeezing of the convective boundary layer, then a conductive reheating of the lithosphere. The main difference with the first experiment is the higher amplitudes of the signals.

experiment, the magnitude of the surface observables do not show significant variations. This is not the case for the shape of these observables. As soon as the plume reaches the boundary layer, it is swept along by the. plate. Consequently, it is stirred downstream and squeezed upstream, as described by Sleep [1987]. The swell acquires progressively an asymmetrical cross section which is reminiscent of the one of the Hawaiian swell.

In the present case, the two stages of the swell evolution are not observed. Due to the drift of the plate, thermal erosion can not operate whereas the mechanical erosion takes place, prohibiting any cumulative effect of these two processes. The squeezing of the boundary layer is quasi-instantaneous and permanent. Consequently, it is worth noting that the rise of the swell at its front has to be related to the convective geometry rather than to the uplift rate. Downstream, the boundary layer is progressively restored as the heat advected by the plume diffuses into the lithosphere. This results in a weak reheating consistent with the lack of surface heat flow anomaly. The dynamical effects are responsible for the swell topography at its front while a reheating process accounts for the topography at its rear. It has to be stressed that the swell extends on a period of 90 m.y. which is twice as long as the subsidence of the Hawaiian swell. This contrast does not necessarily reflect a discrepency between the model and the observations. First, 


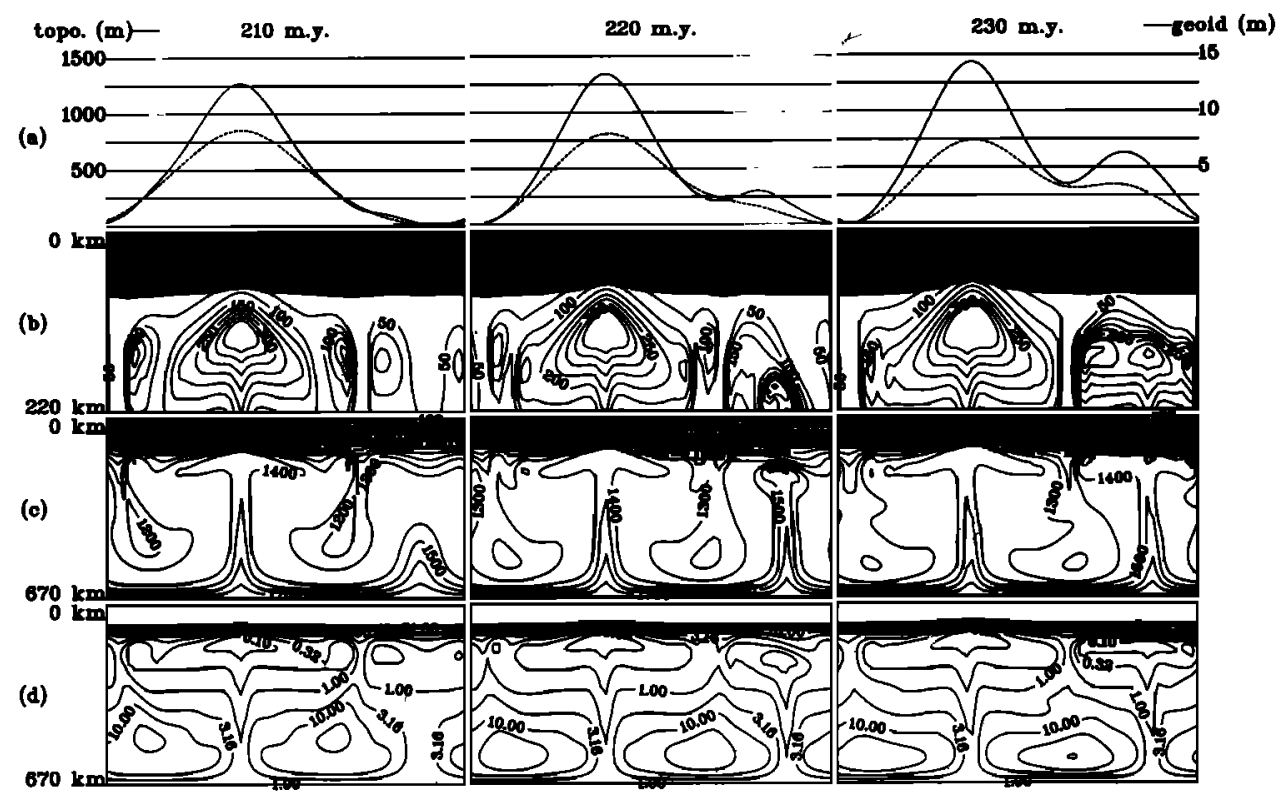

Fig. 4. (continued)

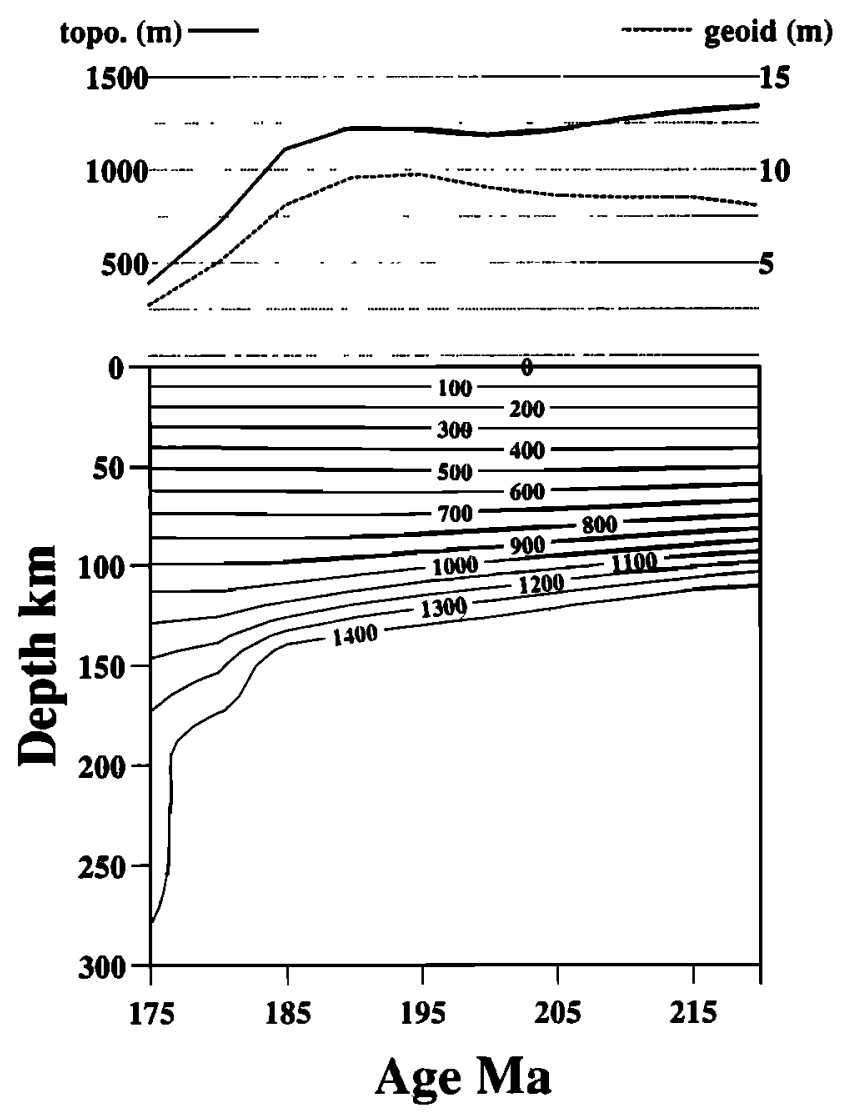

Fig. 5. Evolution of the temperature profile through the center of the plume for the second experiment (shown in Figure 4).

the downstream termination of the swell could be due to the development of a second plume close to the right side of the box. Second, in the present model the lithosphere is older, i.e., thicker, than the Hawaiian lithosphere and thus requires more time to be cooled.

Although it is difficult to infer the results for a younger lithosphere (<100 m.y.), we can just mention that, following Crough's predictions, the older the lithosphere involved in a reheating process, the larger is the horizontal extension of the swell.

\section{Conclusions}

The numerical experiments performed in the present study are far from describing the expected complexity of the plume-lithosphere interaction. Simplifications concern not only the heating mode, the convective layer thickncss, the two-dimensional geometry, but mainly the viscosity laws : they do not consider the stress dependence nor the partial melting which might have dramatic eflects. As a consequence, these experiments have no pretention of bringing definitive answers, but they just shed some light on the way how some mechanisms might account for hotspot swells.

No important thinning of the lithosphere needs to be invoked to account for the swells amplitudes or for the weak apparent compensation depths. These observations are easily explained in the case of a plume-lithosphere interaction restricted to the lowermost part of the thermal lithosphere (below the $800^{\circ} \mathrm{C}-900^{\circ} \mathrm{C}$ isotherm). This horizon is weak enough to be involved in the convective flow and can be considered as the upper boundary layer of the convective mantle. This is consistent with the interpretation of hotspot swell proposed by Fleitout and Moriceau [1991] as the effect of a thermal anomaly localized just below a visco-elastic lithosphere.

Considering the magnitude of the stress induced on this horizon by the convective flow, its thinning is casily and rapidly realized. This mechanism is in fact similar to the one proposed by Crough [1978], but here a mechanical erosion rather than a conductive reheating is operating. Mechanical erosion is a best candidate to account for a very rapid initial uplift of the swclls. The rate at which this erosion can operate is controlled by the pressure dependence of the viscosity. Accordingly, the introduction of a stressdependent viscosity and of the effects of partial melting is required in order to quantify preciscly this process. 

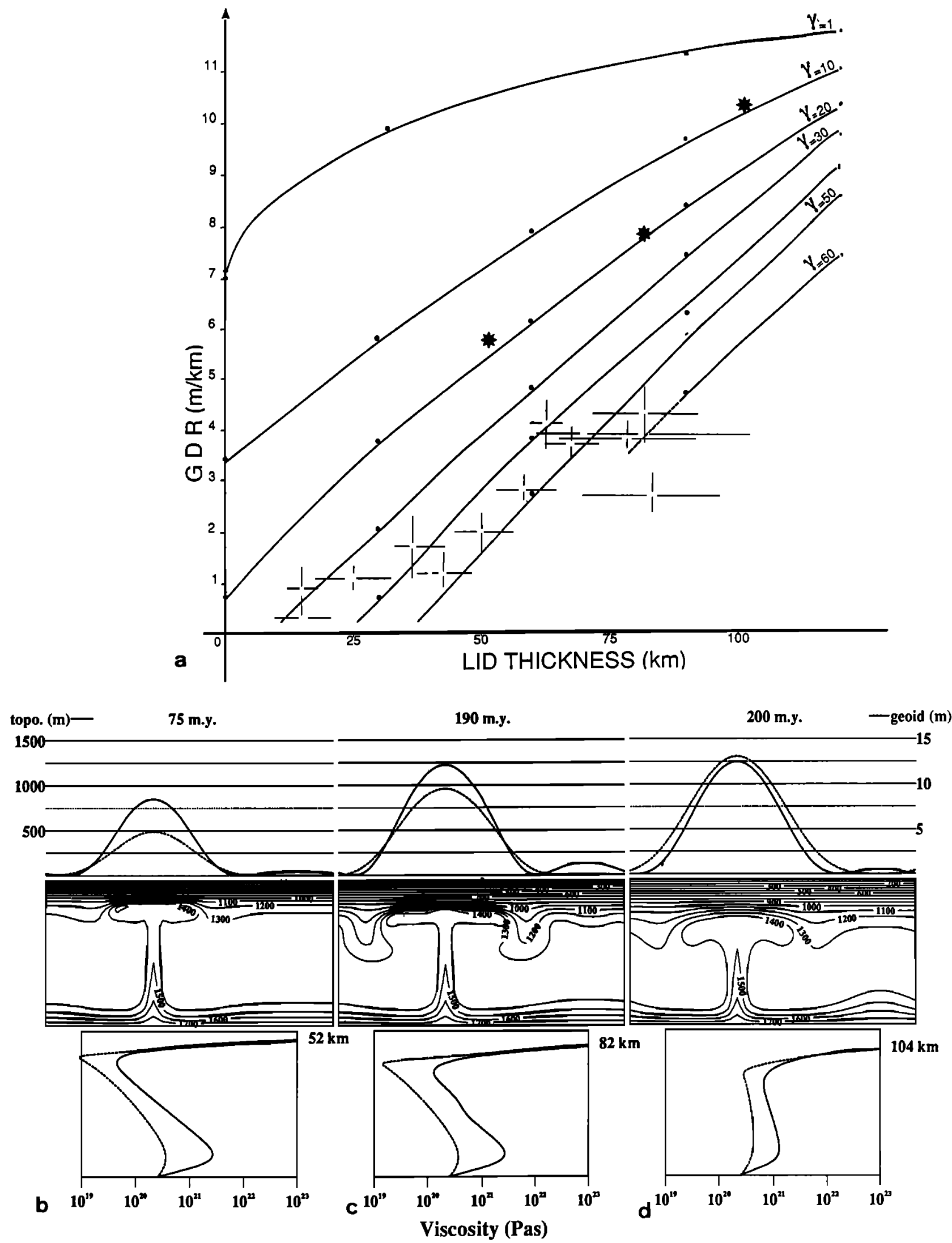

Fig. 6. (a) Geoid to depth ratios as a function of lithosphere thickness : comparison of the GDR deduced from cases 1,2 and 4 (asterisks) with the GDR computed by the two-layer modcl of Ceuleneer et al. [1988] (curves). In that model the viscosity drops by a factor $\gamma$ between a depth of $220 \mathrm{~km}$ and the base of the overlying conductive lid. Crosses indicate the GDR estimated over 23 hotspots by linear regression of geoid anomalies to residual depths [Monnereau and Cazenave, 1988]. (b), (c) and (d) Gcoid and topography, temperature field and viscosity profiles (dashed curve in the plume, solid curve mean profile) for cases 1,2 and 3 respectively. Note that the contrast in the viscosity structure below the lithosphere is consistent with the contrast needed in the two-layers model in order to get the same GDR. 


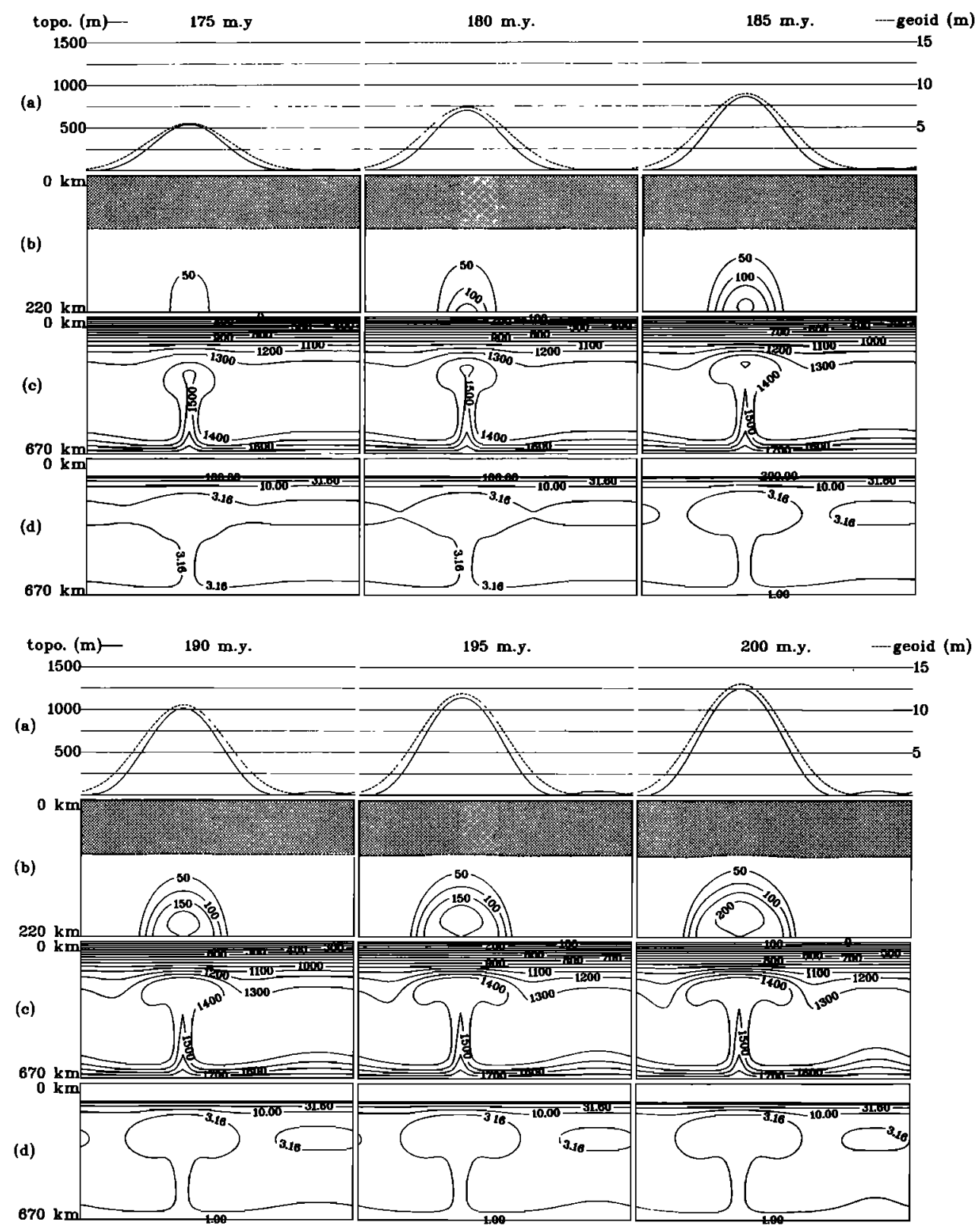

Fig. 7. Plume-lithosphere interaction with newtonian rhcology and basal heating. Third experiment : $E^{*}=65 \mathrm{~kJ} \mathrm{~mole}^{-1}, \mathrm{Vc}=0.8 \mathrm{~m}^{3}$ mole $\mathrm{e}^{-1}$, the lithosphere is $110 \mathrm{m.y}$. old at the start of the experiment. With this less depth-dependent viscosity law, we observe a much less efficient dynamical erosion.

TABLE 1. Numerical Value of Geophysical Constants

\begin{tabular}{llrl}
\hline & \multicolumn{1}{c}{ Description } & \multicolumn{1}{c}{ Value } & \multicolumn{1}{c}{ Unit } \\
\hline$g$ & acceleration of gravity & 9.8 & $\mathrm{~m} \mathrm{~s}^{-2}$ \\
$\rho_{m}$ & mantle density & 3300 & $\mathrm{~kg} \mathrm{~m}^{-3}$ \\
$\boldsymbol{P}_{w}$ & water density & 1000 & $\mathrm{~kg} \mathrm{~m}^{-3}$ \\
$\boldsymbol{\alpha}$ & coefficient of thermal expansion & $3 \times 10^{-5}$ & ${ }^{\circ} \mathrm{C}^{-1}$ \\
$\boldsymbol{K}$ & thermal diffusivity & $1 \times 10^{-6}$ & $\mathrm{~m} \mathrm{~m}^{2} \mathrm{~s}^{-1}$ \\
$\eta$ & reference viscosity & $2.5 \times 10^{20}$ & $\mathrm{~Pa} \mathrm{~s}$ \\
$\boldsymbol{L}$ & upper manle thickness & $670 \times 10^{3}$ & $\mathrm{~m}$ \\
$T_{\text {surface }}$ & temperature at the surface & 0 & ${ }^{\circ} \mathrm{C}$ \\
$T_{670}$ & temperature at $670 \mathrm{~km}$ & 1800 & ${ }^{\circ} \mathrm{C}$ \\
$\Delta T$ & temperature drop $T_{670}-T_{\text {surface }}$ & 1800 & ${ }^{\circ} \mathrm{C}$ \\
$T_{m}$ & mean asthenospheric temperature & 1350 & ${ }^{\circ} \mathrm{C}$ \\
$v$ & Poisson ratio & 0.5 & \\
$E$ & Young's modulus & $10^{12}$ & $\mathrm{~N} \mathrm{~m}^{-2}$ \\
\hline
\end{tabular}




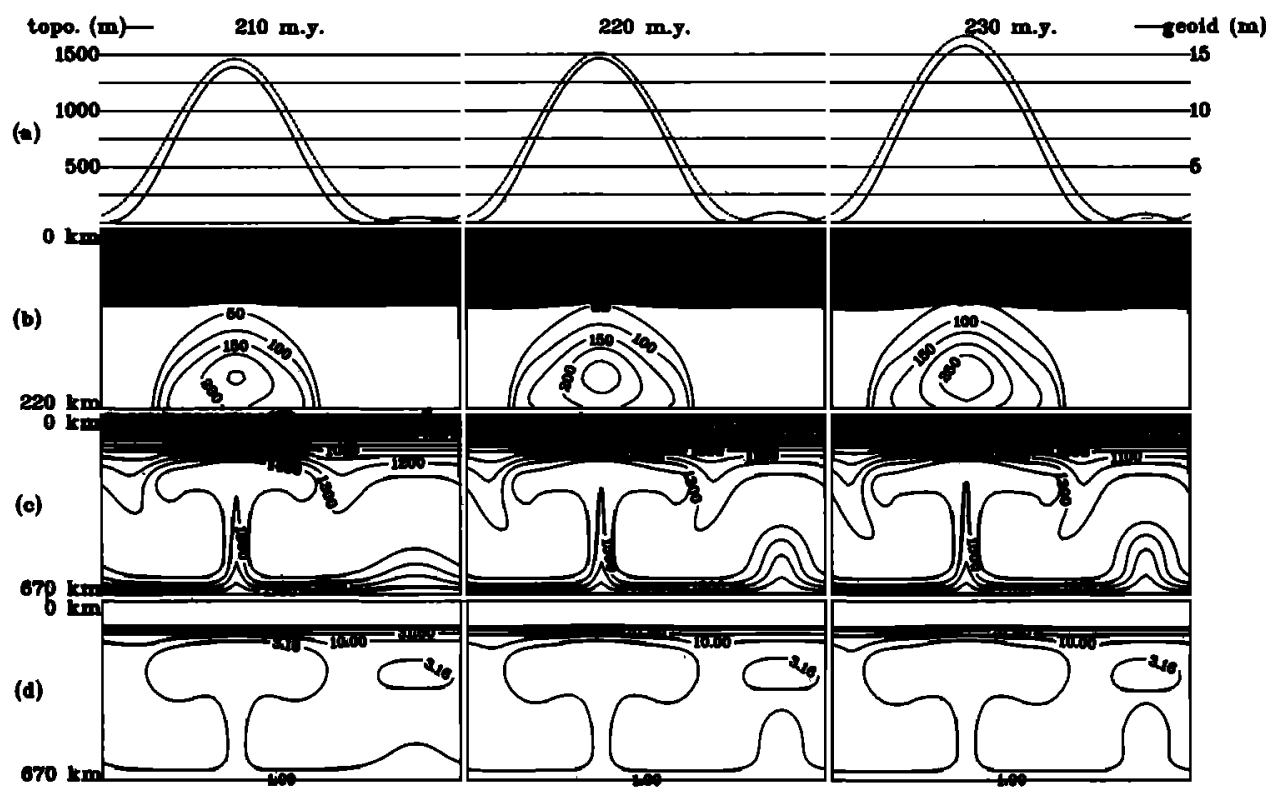

Fig. 7. (continued)

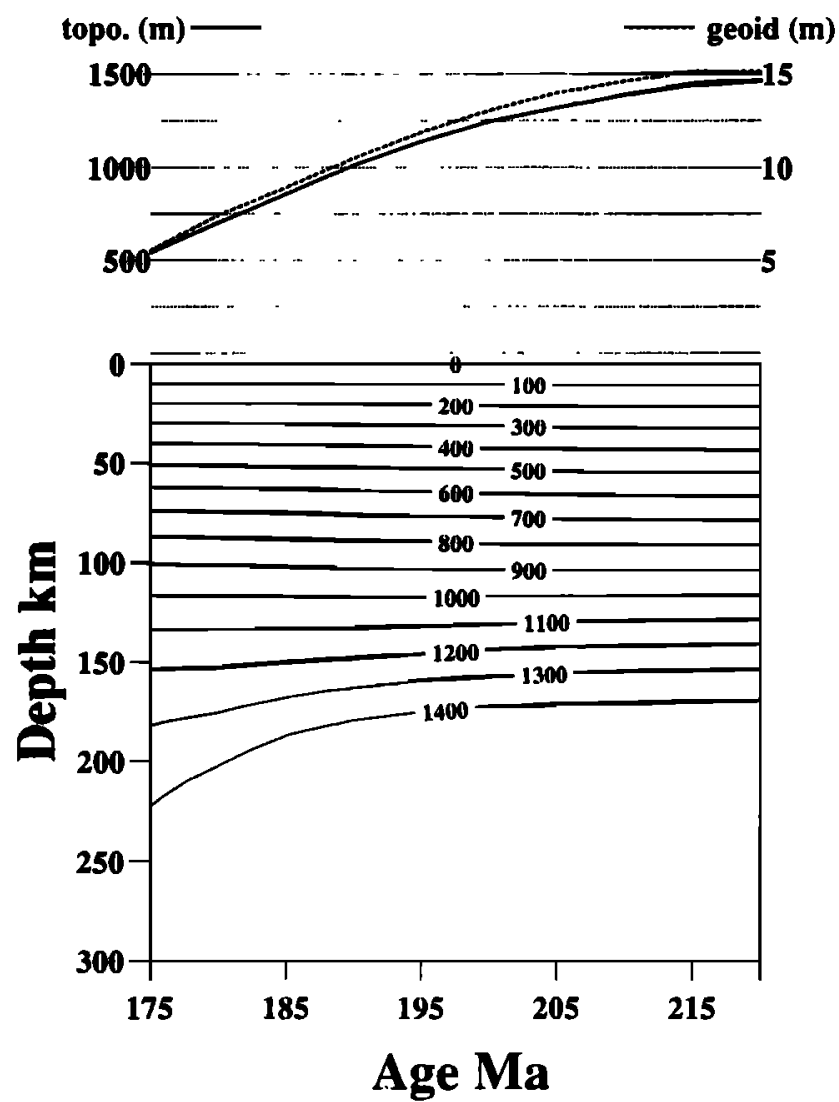

Fig. 8. Evolution of the temperature profile through the center of the plume for the third experiment (shown in Figure 7). The reheating of the lithosphere is, in this case, roughly progressive. The distinction between dynamical and conductive effects is no longer observable.
Thermal conduction is a too sluggish process to contribute to the early uplift of the swell, but this effect can become significant after several tens of millions of years, in the case where the plume-lithosphere interaction operates at the same place. This effect is thus marginal for most swells which occur on a moving platc. However, it could account for the anomalously high amplitudes of Azores, Crozet and Cape Verde swells which are actually located on quasi motionless plates relative to the hotspot referential [Morgan, 1981]

Finally, we would like to stress on the importance of the constraints brought by observed trends, compared to isolated measurements. As a matler of fact, it is always possible to find a combination of paramcters which matches the data for a single hotspot. As shown by Courtney and White [1986], the data at the Cape Verde swell can be plainly explained by an anomalously low viscosity of the entire upper mantle in the vicinity of the hotspot. However, it seems very difficult to invoke any systematic variation of mantle propertics from one hotspot to the next in order to account for the increase of swell amplitude with age.

Conversely, in the case of swells resulting from the mechanical erosion of the ductile part of the lithosphere, the observed trend is casily explained by the thickening with age of this plastic horizon.

In conclusion, mechanical erosion of the lithosphcre is a plausible swell formation mechanism. It can account for some major observations, as the rapid initial uplift, the lack of heat flow anomaly, the increasing trend of the swcll amplitudes with plate age. This model lies just in between thermal thinning and dynamical support models: most of signal is likely caused by some kind of thinning, but the resulting thermal anomaly is restricted to a ductile horizon 


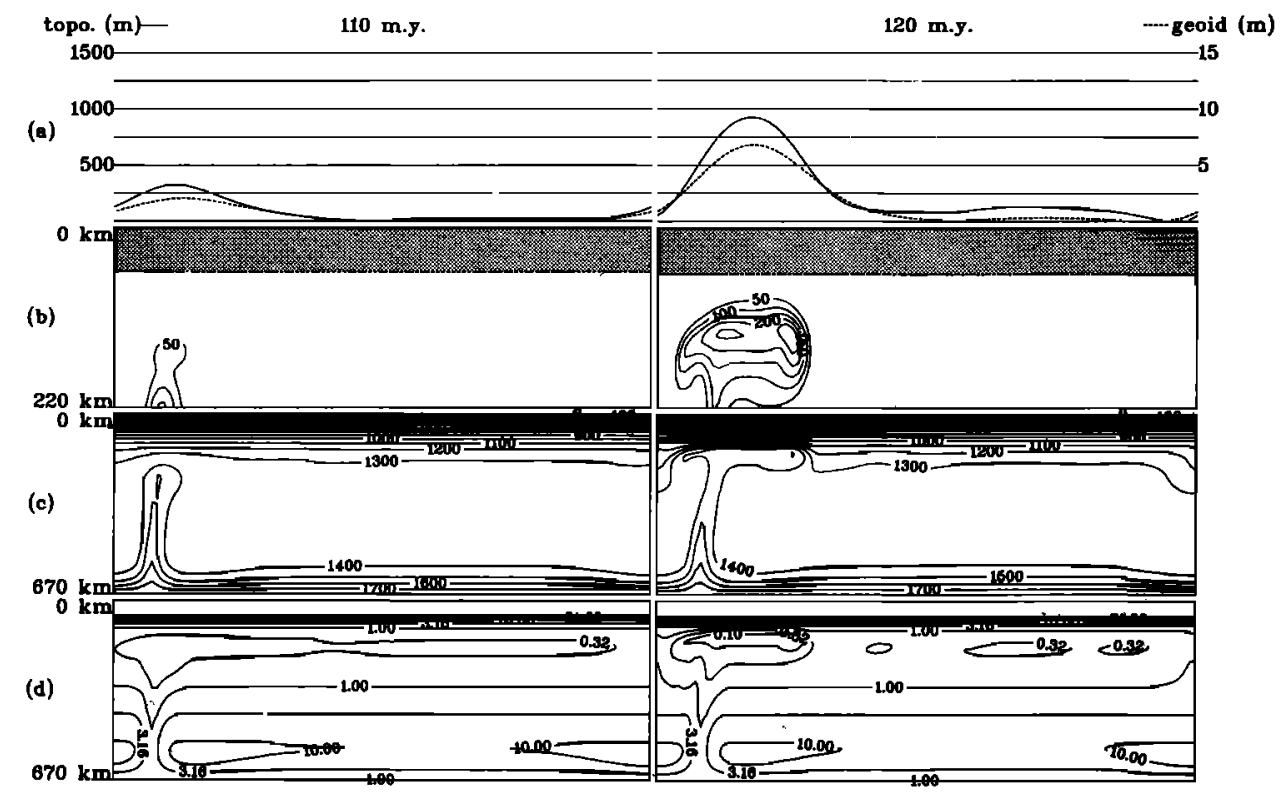

Fig 9(a).

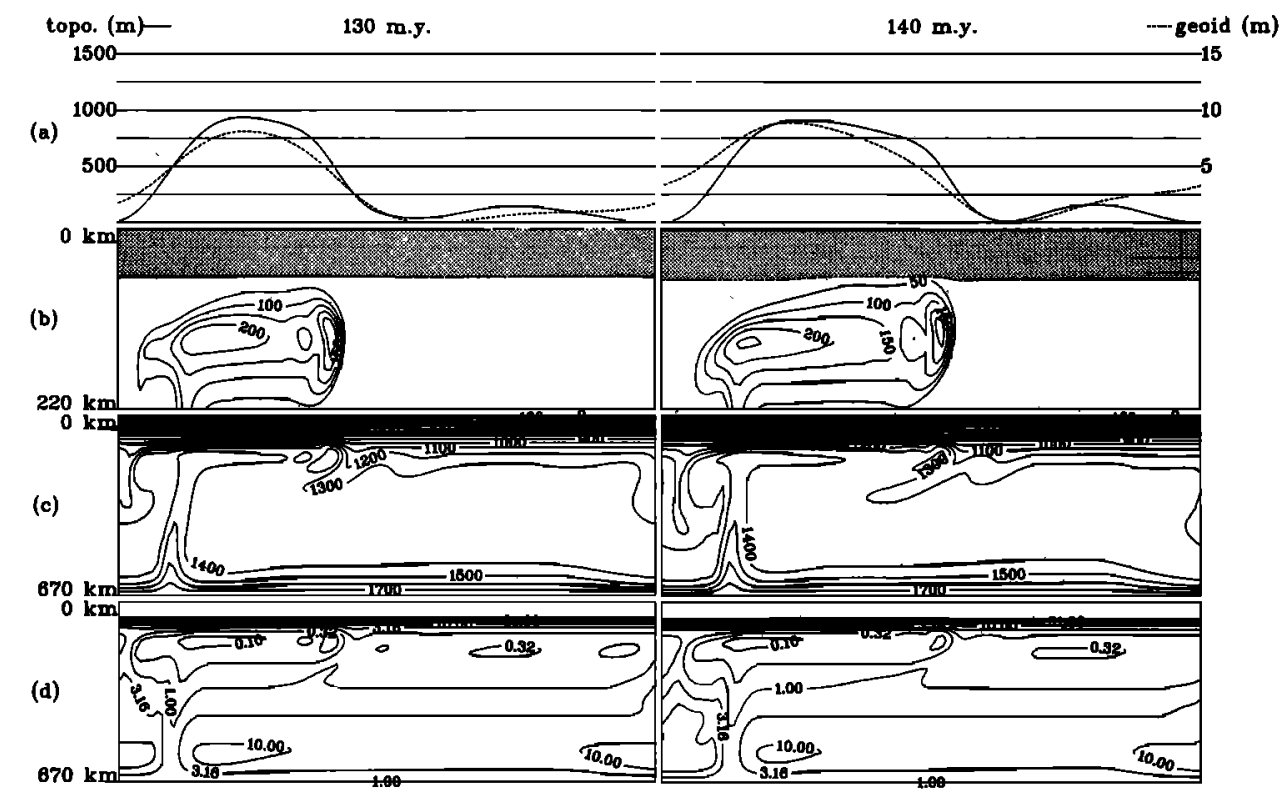

Fig. 9. Plume-lithosphere interaction with Newtonian rheology and basal heating. Fourth experiment: moving plate, $E^{*}=130 \mathrm{~kJ} \mathrm{~mol}^{-1}, V c=4 \mathrm{~m}^{3} \mathrm{~mol}^{-1}$, the lithosphere is $50 \mathrm{~m} . \mathrm{y}$. old at the start of the experiment; the plate velocity is $2 \mathrm{~cm} / \mathrm{yr}$. In that more realistic case the dynamical erosion and the conduclive reheating are continuous, but they act at different places, resulting in an asymmetric swcll strikingly reminiscent of the Hawaiian swell.

where the isostasy hypothesis is not valid, i.e., where the dynamical effects can not been neglected.

Acknowledgments. We would like to thank U. Christensen and an anonymous reviewer for a careful review of the manuscript and for constructive comments.
We also thank G. Ceuleneer for his constant altention in the writing of the manuscript and for stimulating discussions. This study was supported by the Centre National d'Etudes Spatiales. This paper is contribution CNRS-INSU-DBT nº 148, thème "Instabilités." 


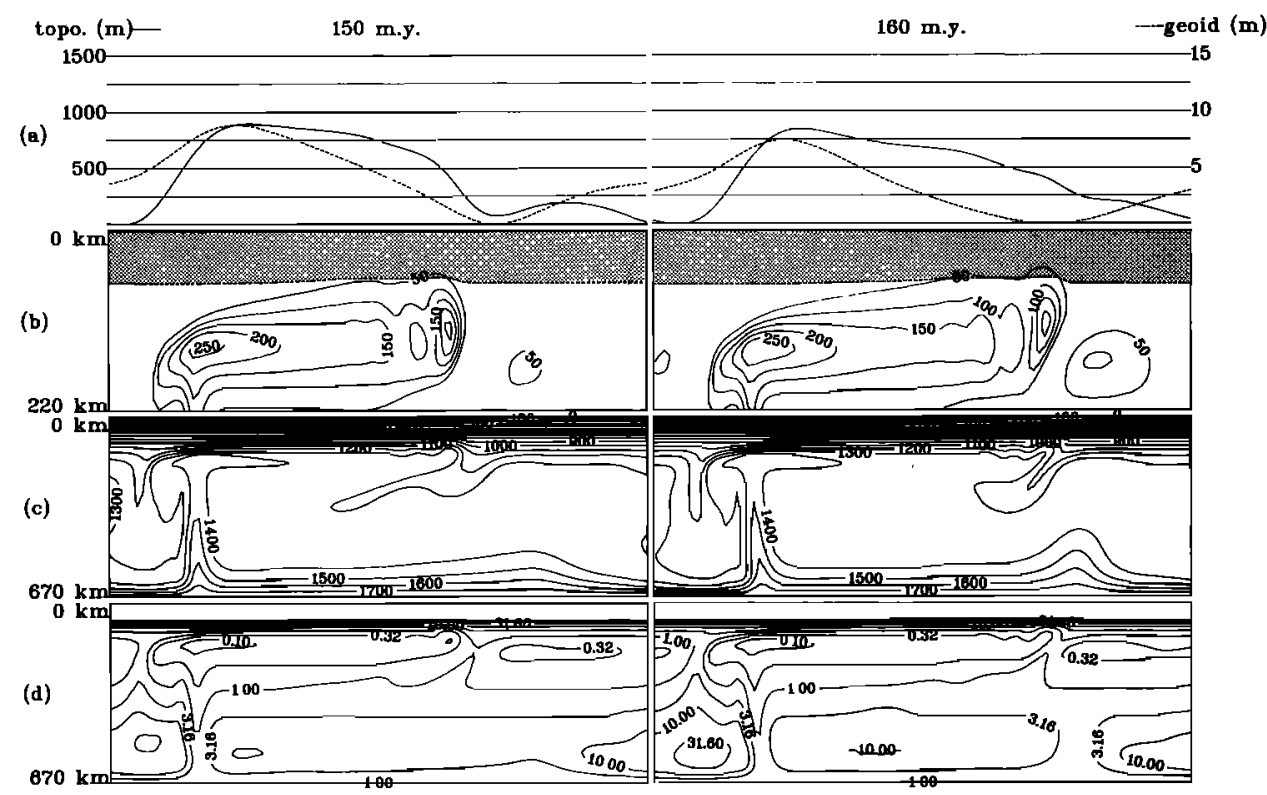

Fig 9(c).

\section{REFERENCES}

Arquis, E., and J. P. Caltagirone, Interacting convection between fluid and open porous layers, ASME Winter Annual. Meeting, Boston, Massachusetts, 87-WA/HT24, 1987.

Calmant, S., J. Francheteau, and A. Cazenave, Elastic layer thickening with agc of the oceanic lithospherc: a tool for prediction of the age of volcanoes or oceanic crust, Geophys. J. Int., 100, 56-67, 1990.

Cathles, L.M., The Viscosity of the Earth's Martle, 386 pp., Princeton Universily Press, Princeton N.J., 1975.

Ceuleneer, G., M. Rabinowicz, M. Monnereau, A. Cazenave, and C. Rosemberg, Viscosity and thickness of the sub-lithosphere low viscosily zone: constraint from geoid and depth anomalies over occanic swclls, Earth Planet. Sci. Lelt., 89, 84-102, 1988.

Christensen, U. R., Convection with pressure and temperature dependent non-Newlonian rheology, Geophys. J. R. Astron. Soc., 77, 242-284, 1984.

Courtney, R. C., and R. White, Anomalous heat flow and geoid accross the Cape Verde rise: Evidence for dynamic support from a thermal plume in the mantle, Geophys. $J$. R. Astron. Soc., 87, 815-887, 1986.

Craig, C. H., and D. P. McKenzie, The existence of a thin low viscosity layer beneath the lithosphere, Earth Planet. Sci. Lett., 78, 420-426, 1986.

Crough, S. T., Thermal origin of mid-plate hotspot swells, Geophys. J. R. Astr. soc., 55, 451-469, 1978.

Fleitout, L., and C. Moriceau, Topography and geoid anomalies due to density heterogeneities at the base of thermal lithosphere: Application to occanic swclls and small-wavelength geoid lineations, Geophys. J. Int., 107, 265-277, 1991.

Haxby, W. F., and D. L. Turcotte, On isostatic geoid anomalies, J. Geophys. Res., 83, 5473-5478, 1978.

Kirby, S. A., Rheology of the lithosphere, $R e v$. Geophys., 21, 1458-1487, 1983.
Marty, J. C., A. Cazenave, and B. Lago, Geoid anomalies across Pacific fracture zones, Geophys. J., 93, 1-23, 1988.

McNutt M.K., Temperature beneath midplate swells : the inverse problem, in Seamounts, Islands, and Atolls, Geophys. Monogr. Ser., vol. 43, edited by B.H. Keating, P. Fryer, R. Batiza and G. N. Boehlert., pp. 123-132, A.G.U., Washington, D. C., 1987.

Monnereau M., and A. Cazenave, Variation of the apparent compensation depth of hot spots swells with age of plate, Earth Planet. Sci. Lett., 91, 179-197, 1988.

Monnereau M., and A. Cazenave, Depth and geoid anomalies over oceanic hotspot swells: A global survey, J. Geophys. Res., 95, 15429-15438, 1990.

Morgan, W. J., Convective plumes in the lower mantle, Nature, 230, 42-43, 1971.

Morgan, W. J., Hotspot tracks and opening of the Atlantic and Indian oceans, in The Sea, vol. 7, The Oceanic Lithosphere, edited by. Emilian, pp. 443-487, John Wiley, New York, 1981.

Olson, P., and G. Schubert, Plume formation and lithosphere erosion: A comparison of laboratory and numerical experiments, J. Geophys. Res., 93, 15065$15084,1988$.

Parsons, B., and S. F. Daly, The relationship between surface topography, gravity anomalies and temperature structure of convection, J. Geophys. Res., 88, 11291144, 1983.

Patankar, S. V., Numerical heat transfert and fluid flow, Series in Computational Methods in Mecanics and Thermal Sciences, edited by W. J. Minkowycz and E. M. Saparrow, 197 pp., Hemisphere Publishing Corporation, New York, 1980.

Rabinowicz, M., B. Lago, and C. Froideveaux, Thermal transfer between the continental asthenosphere and oceanic subducting lithosphere: Its effect on subcontinental convection, J. Geophys. Res., 85, 1839 1853, 1980. 
Robinson, E. M., B. Parsons, and S. F. Daly, The effect of a shallow low viscosity zone on the apparent compensation of mid plate swells, Earth Planet. Sci. Lett., 82, 335-348, 1987.

Robinson, E. M., B. Parsons, and M. Driscoll, The effect of a shallow low viscosity zone on the mantle flow and geoid anomalies at fracture zones, Geophys. J., 93, 2543, 1988.

Schmeling, H., Variable viscosity convection in a compressible upper mantle and the thickness of continental lithosphere, in Glacial Isostasy, Sea-level and Mantle Rheology, edited by R. Sabadini et al., pp. 607-636, Kluwer Academic, Boston, Mass., 1991.

Sleep, N. A., Lithospheric heating by mantle plume, Geophys. J. R. Astron. Soc., 91, 1-11, 1987.

Von Herzen, M. J. Cordrey, R. S. Detrick, and Changle Fang, Heatflow and the thermal origin of hot spot swells: The Hawaiian swell revisited, J. Geophys. Res., 94, 13783-13799, 1989.

Yuen D. A., and L. Fleitout, Thinning of the lithosphere by small scale convective destabilisation, Nature, 313, 125-128, 1985.

E. Arquis, MASTER-ENSCPB, 351 cours de la libération, 33405 Talence cedex, France.

M. Monnereau and M. Rabinowicz, GRGS-CNES, 18 avenue E. Belin, 31055 Toulouse cedex, France.

(Received March 20, 1991;

revised June 29, 1992;

accepted July 11, 1992.) 